\title{
Lifts for Emergency Evacuation in Apartment Buildings
}

\author{
THAN SINGH SHARMA ${ }^{1}$, YAPING HE ${ }^{2}$ and MAHEN MAHENDRAN ${ }^{1}$ \\ ${ }^{1}$ School of Urban Development, Queensland University of Technology, Brisbane, Australia \\ ${ }^{2}$ School of Engineering, University of Western Sydney, Sydney, Australia
}

\begin{abstract}
A research project was undertaken to investigate whether the lifts can be used as an alternate emergency evacuation route in apartment buildings. The important parameters in relation to the issues were divided into three categories: human behavioural response, fire hazards and lift operational mechanism. The parameters relating to human behavioural response were modelled and analysed as a stochastic process. The parameters relating to fire hazards were analysed using the concept of fire safety index while the parameters relating to operational mechanism were analysed using probabilistic models. An integrated approach of risk assessment was developed based on the Multi-Objectives Decision Analysis method. The results for lift and stair systems were compared and the feasibility of using lifts with design modifications was analysed. The outcome of the research has shown that lifts as an alternate evacuation facility with enhanced level of safety have potential to improve evacuation efficiency, particularly for aged and disabled persons. Partial evacuation using lifts with a protected lobby is possible. The risk involved in total evacuation using lifts with double protection is comparable with stair-alone evacuation.
\end{abstract}

KEYWORDS: apartment building, aged, disabled, emergency evacuation, injury, lift, panic, multiobjective decision analysis, risk assessment

\section{NOMENCLATURE LISTING}

$\begin{array}{ll}A & \text { comparison matrix } \\ a & \text { element of comparison matrix } \\ b & \text { element of priority vector } \\ C I & \text { consistency index } \\ C R & \text { consistency ratio } \\ \text { LMR } & \text { lift machine room } \\ n & \text { number of parameters } \\ p & \text { parameter measure } \\ R & \text { risk } \\ R_{A} & \text { acceptable risk }\end{array}$

$\begin{array}{ll}t_{L T} & \text { lift transportation time }(\mathrm{s}) \\ t_{L W} & \text { lift waiting time }(\mathrm{s}) \\ t_{S T} & \text { stair traveling time }(\mathrm{s}) \\ v & \text { value function or normalization function } \\ W & \text { weight vector } \\ w & \text { weight vector element } \\ \text { Greek } & \\ \lambda & \text { eigenvalue of comparison matrix } \\ \text { Subscript } \\ i, j \quad \text { index }\end{array}$

\section{INTRODUCTION}

Over the past two decades, the works of Klote [1] and many others [2,3] have led to a better understanding of many problems associated with the use of lifts during fire emergencies. Subsequent to the WTC twin tower collapse on September 11, 2001, researchers have focused their efforts on the use of lifts as an alternative evacuation facility in buildings $[4,5]$. Some researchers believe that if adequate emergency escape lifts were available at the WTC, more occupants could have been evacuated in a shorter period of time and the extent of the fatality might have been reduced [6]. Building evacuation efficiency has been the focus of many researchers [7]. The lift evacuation can be considered as an alternative resource if it is efficient, reliable and safe from the fire point of view. This research is further extended to compare the probable time of building evacuation under uncertainties associated with human, social, behavioural and physical movement (with a priori heuristics of the lift domain) and the probable time when the evacuees are predicted to become incapacitated during exposure of fire effluents under variable conditions (such as wind speed and building height). Lifts can provide a safer means of evacuation for the aged and disabled, who may not be expected to evacuate promptly, efficiently and unassisted using the stairs during fire emergencies.

Of all types of high rise buildings, apartment buildings may have greater need to improve the efficiency of emergency evacuation by use of lifts. The occupants of apartment or residential buildings have wider age distribution and greater proportion of people with disabilities than office and other types of high rise buildings [8]. Fire statistics indicates that the likelihood of fatality is very significant (28.5\%) for occupants 
attempting to evacuate residential buildings [9]. This paper presents the research overview and outcomes on the use of lifts for emergency evacuation in apartment buildings. It describes that the use of lifts does not reduce the level of life safety in a high rise apartment building, if appropriate design and fire safety measures are implemented. The strategy of combined lifts and stairs evacuation has significant advantage over stair-alone evacuation.

\section{RECENT DEVELOPMENTS IN THE SUBJECT AREA}

Deliberations over the years resulted in varying philosophies toward the use of lifts for emergency evacuation. Due to the influences from the fire fighting communities, the emphasis has always been placed on the use of lifts for fire fighting only, and not for general public use [10].

A workshop on the "Use of Elevators in Fires and Other Emergencies" was held in March 2004 in Atlanta, Georgia. The consensus of workshop attendees was that the lift operation should work only at early stage of fire emergency [11]. Recommendations were also made to the ASME A17 Emergency Operation Subcommittee for further research addressing the technical issues and develop performance requirements for lift evacuation system during fire emergencies [11]. NIST funded a research project on "Analysis of the life safety consequences of smoke migration through elevator shafts" [12]. The study was limited to the smoke movement in office buildings with the current infrastructure of lift system. The results showed that unsafe conditions may arise on upper levels through lift shafts during a fully developed fire and the sprinkler systems are able to reduce or minimise the likelihood of unsafe conditions in the buildings. The occupants' evacuation aspects were, however, not considered in this study.

The concept of use of lift for emergency evacuation has been, though not widely, accepted by industry. Reports on design applications can be found in the literature $[13,14]$. Despite the abundance of design proposals, the methodology for risk assessment is still seen as in its infant stage [15]. This paper introduces a new approach to the assessment of risk associated with the use of lift for emergency evacuations. The application of the approach is demonstrated by a case study of a particular high rise apartment building.

\section{MULTI-OBJECTIVES DECISION ANALYSIS AND RISK ASSESSMENT}

The parameters related to the risks in evacuation systems may be multi-dimensional (psychological and physiological issues). The traditional risk assessment approach (i.e. Risk $=$ Probability of Occurrence $\times$ Consequences) is single dimensional in that the consequence is often treated as having a single attribute such as physical injuries or fire cost [16]. However, the possible consequences of fire may not be limited to physical injuries and financial losses. Psychological injuries can also occur after building occupants experience life-threatening situations. The challenge is how to incorporate the multiple parameters that reflect the possible consequences into a single model such that the overall risk of a design can be evaluated.

The Multi-Objectives Decision Analysis (MODA) approach offers a plausible solution. The MODA is defined as an approach to decision making under conditions of complexity, with inherent uncertainty, multiple objectives and different perspectives towards the decision problem [17]. This approach has been successfully used in other fields [18-21]. The MODA approach is based on the Simple Multi-Attribute Rating Technique (SMART) of Edwards [22] and is often used in comparative studies when alternative design options are available. The MODA involves the following steps:

Step 1: Identify concept design options

Step 2: Specify evaluation parameters

Step 3: Specify weights to parameters using analytical hierarchical process (AHP)

Step 4: Determine value functions

Step 5: Analyse the results (sensitivity analysis)

The model is constructed in terms of $n$ evaluation parametric measures $p_{1}, p_{2}, \ldots, p_{n}$, and the overall value of the model is given by

$R=\sum_{i=1}^{n} w_{i} v_{i}\left(p_{i}\right)$ 
where the $w_{i}$ are weights and the $v_{i}\left(p_{i}\right)$ are non-dimensional value functions that normalise dimensional parametric measures $p_{i}(i=1,2, \ldots, n)$ into non-dimensional values between 0 and 1 (or between 0 and 100). When the MODA approach is used for risk assessment, the risk, as defined by Eq. 1, is interpreted as a total of weighted multiple non-dimensional risk attributes. In this study, the risk is considered to broadly fall under three categories i.e. human behavioural response, fire hazards and lift operational mechanism. These issues can lead to the risks of decision uncertainty (a psychological impact), panic (mainly psychological impact), nonfatal and fatal injuries (mainly physiological impact). Although panic is not a frequent event as reported by many researchers for building occupants using fire stairs, the likelihood is that such behaviour might occur when people know they can not escape using evacuation routes such as lifts. The evidence for panic occurring after people knew they could not escape is inconclusive. A low weighting factor was then assigned to this parameter.

\section{Concept Design Options}

Three concept design options were considered, namely unprotected lift lobby, single protection with a fire door and double protection with a fire door and a smoke door. These design options are illustrated in Fig. 1.

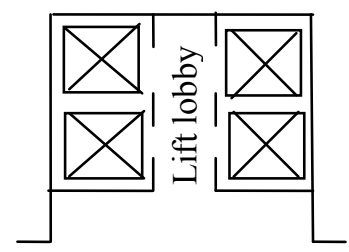

Public corridor

Unprotected lift lobby

(A)

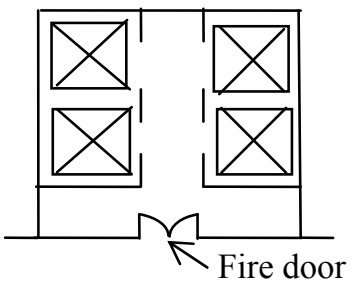

Protected lift lobby

(B)

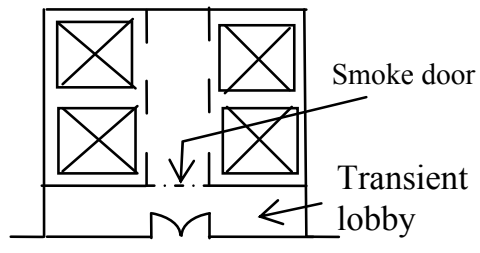

Double protected lift lobby

(C)

Fig. 1. Lift lobby design options.

The use of lifts can be associated with evacuation strategies. Two evacuation strategies, namely use of lifts by the entire building occupant population or a $75-25 \%$ stair-lift split, were considered. In total five concept design options along with alternative evacuation strategies are considered as listed and labeled in Table 1.

Table 1. Concept design options and evacuation strategies

\begin{tabular}{|c|l|}
\hline Concept Design & \multicolumn{1}{c|}{ Illustration } \\
\hline A & Lifts with unprotected lobby for use by $100 \%$ population \\
\hline B & Lifts with protected lobby for $100 \%$ population \\
\hline C & Lifts with double protected lobby for $100 \%$ population \\
\hline D & Stairs for $100 \%$ population (stairs only) \\
\hline E & Stairs used by $75 \%$ population and protected lifts by $25 \%$ \\
\hline
\end{tabular}

The concept design option D (stairs with smoke transient lobby) is an option for which the associated risk is deemed acceptable. This option was included as a reference for the comparative study.

\section{Evaluation Parameters}

Main issues of human behavioural response and life safety can cause decision uncertainty, panic and injuries (nonfatal and fatal) in the lift and stair systems. The risks are compared based on the following assumptions:

- decision uncertainties that may be caused by longer lift waiting time or longer travelling time in the stairs.

- panic that may be caused by perceived threat or unavailability of evacuation route (lifts or stairs). 
- injuries (nonfatal and fatal) that occur if evacuees are exposed to life threatening conditions caused by fires and precipitated from pre-existing health conditions.

Seven parameters were identified to be directly related to risk and are listed in Table 2.

Table 2. Risk related parameters

\begin{tabular}{|l|l|c|c|}
\hline Risk Category & \multicolumn{1}{|c|}{ Parameter } & Symbol & Unit \\
\hline $\begin{array}{l}\text { Decision } \\
\text { uncertainty }\end{array}$ & $\begin{array}{l}\text { Lift waiting time }\left(t_{L W}\right) \text { and transportation time }\left(t_{L T}\right) \\
\text { or stair traveling time }\left(t_{S T}\right)\end{array}$ & $p_{1}$ & Second \\
\cline { 2 - 4 } & Number of evacuees in queue in lift or stair lobbies & $p_{2}$ & Person \\
\cline { 2 - 4 } & Proportion of aged and disabled evacuees & $p_{3}$ & $\%$ \\
\hline Panic & Non-availability of evacuation route & $p_{4}$ & $\%$ \\
\cline { 2 - 4 } & Time to exceed tenability limit for visual threat & $p_{5}$ & Second \\
\hline $\begin{array}{l}\text { Injuries } \\
\text { (nonfatal and } \\
\text { fatal) }\end{array}$ & Safety index & $p_{6}$ & - \\
\cline { 2 - 4 } & $\begin{array}{l}\text { Presence of fire effluents in evacuation route (e.g., } \\
\text { temperature, concentrations of smoke and asphyxiant } \\
\text { toxic gases.) }\end{array}$ & $p_{7}$ & - \\
\hline
\end{tabular}

\section{Specifying Weights}

Each parameter is given a degree of importance (weighting). The Analytical Hierarchical Process (AHP) approach, developed by Saaty [23], is extensively used in multi-objectives decision making method for giving weighting. The weights are estimated from the data of survey reports and statistics. Although, data of survey reports and statistics may or may not be directly related to parameters of lift and stair systems, the data of similar nature are selected for both systems. Using these weightings, all the design options are analysed.

\section{Analytical Hierarchical Process for Risk Priorities}

The AHP procedure involves three basic steps such as hierarchical structure, comparative judgments to obtain pair-wise comparison data on elements of the hierarchical structure and synthesis of priorities or constructing an overall priority rating. Three hierarchical levels of "decision uncertainty, panic and injuries (nonfatal and fatal)" are given to identify parameters for pair-wise comparisons. The hierarchic levels are based on the degree of hazards from psychological to physiological effects on a time sequence during the evacuation procedure. The impacts lie on a continuum from little or no effect at low level to relatively severe incapacitation at high levels.

The pair wise comparison at a given level can be reduced to a number of $n \times n$ square matrices $A=\left[a_{i j}\right]_{n n}$ which is referred as the comparison matrix. Saaty [23] recommended numerical values $1,3,5,7$ and 9 for making subjective pair-wise comparisons and constructing the matrix. The increasing numerical values indicate increasing importance. The weight vector, $W=\left[w_{1}, w_{2}, \ldots, w_{n}\right]$, is computed on the basis of Saaty's eigenvector procedure in the following two steps:

The pair-wise comparison matrix, $A=\left[a_{i j}\right]_{n n}$, is normalised by the following equation:

$$
a^{*}{ }_{i j}=\frac{a_{i j}}{\sum_{i, j=1}^{n} a_{i j}}
$$

The weight for the $i$ th parameter $(i=1,2, \ldots, n)$ is then computed by the following equation: 
$w_{i}=\frac{\sum_{j=1}^{n} a_{i j}^{*}}{n}$

It follows that

$\sum_{i=1}^{n} w_{i}=1$

Vector $W$ is the eigenvector and a scalar $\lambda$ exists such that

$A W=\lambda W$

The scalar $\lambda$ is the eigenvalue of matrix $A$. The maximum eigenvalue $\lambda_{\max }$ is an important validating parameter in AHP [23]. The $\lambda_{\max }$ is used as a reference index to screen information by calculating the consistency ratio $(C R)$ of the estimated vector. When the matrix is perfectly consistent, $\lambda_{\text {max }}$ equals to $n$. If the matrix is not perfectly consistent, $\lambda_{\max }$, is greater than $n$. The larger the $\lambda_{\max }$, the greater is the degree of inconsistency. To calculate $C R$, the consistency index $(C I)$ for each matrix of order $n$ can be obtained from equation:

$C I=\frac{\lambda_{\text {max }}-n}{n-1}$

Consistency index $C R$ can be calculated using the following equation:

$C R=\frac{C I}{R I}$

where $R I$ is the random inconsistency index. If $C R<0.1$, the comparisons are consistent and if $C R>0.1$, the comparisons are of inconsistence judgment [23].

Comparison matrices are developed for assigning the priorities for three levels of risks. The priorities are the numerical ranks measured on a ratio scale [23]. The priorities are obtained from dividing the judgment, or the value of a column element by the sum of all the element values. Physiological impact is considered more important then psychological impact for causing nonfatal or fatal injuries. For example, the psychological impact on a building occupant experiencing a fire incident can be compared with the physiological impact in a $2 \times 2$ matrix. Miller [9] reported that out of 131 victims of residential fires, 15 victims acted in irrational or attention seeking ways. Hence, nearly $11 \%$ or approximately one in nine victims experienced psychological impact and the remaining victims experienced physiological impact. Therefore, psychological impact is assigned a value of 1 and the physiological impact a value of 8 in the first column of the matrix as shown in Table 3. Eight signifies as physiological impact eight times more risky than psychological impact. The reciprocal value is shown in cell $(1,2)$ of the table, which signifies that psychological impact is eight times lower in risk than physiological impact.

The element of the priority vector presented in the last column of Table 3 is calculated according to the following equation:

$b_{j}=\frac{a_{j j}}{\sum_{i=1}^{n} a_{i j}}$

It follows that 
The maximum eigenvalue $\left(\lambda_{\max }\right)$, consistency index $C I$ and consistency ratio $C R$ are calculated according to Eqs. (5), (6) and (7) for matrix consistency.

Table 3 . The $2 \times 2$ matrix for priorities of lift evacuation.

\begin{tabular}{|l|c|c|c|}
\hline & Psychological Impact & Physiological Impact & Priorities \\
\hline Psychological Impact & 1 & $1 / 8$ & 0.11 \\
\hline Physiological Impact & 8 & 1 & 0.89 \\
\hline
\end{tabular}

The psychological impact can be caused by decision uncertainty, panic and nonfatal injury. The comparison matrix for these three parameters is then a $3 \times 3$ matrix as shown in Table 4 . Parameter decision uncertainty is assigned the base value of 1 . Panic is considered to have more severe consequences than decision uncertainty for psychological impact and is assigned the value of 5 in cell $(2,1)$ of Table 4 . Likewise, nonfatal injury is considered to be of more importance than other parameters and therefore assigned the value of 9 . Similarly, 2 is assigned to nonfatal injury in comparison to panic in $(3,2)$.

Table 4 . The $3 \times 3$ matrix for priorities of psychological impact.

\begin{tabular}{|l|c|c|c|c|}
\hline & $\begin{array}{c}\text { Decision } \\
\text { Uncertainty }\end{array}$ & Panic & $\begin{array}{c}\text { Nonfatal } \\
\text { Injury }\end{array}$ & Priorities \\
\hline Decision Uncertainty & 1 & $1 / 5$ & $1 / 9$ & 0.066 \\
\hline Panic & 5 & 1 & $1 / 2$ & 0.319 \\
\hline Nonfatal Injury & 9 & 2 & 1 & 0.615 \\
\hline
\end{tabular}

In the matrix for priority of physiological impact, panic was used as a reference attribute and was assigned the value of 1 . Nonfatal injury has greater physiological impact on occupants than panic and is assigned a value of 3 for the $(2,1)$ element in the matrix (see Table 5). Fatal injury is considered to be of extreme importance and therefore is assigned an intensity of importance to a value of 9 . The risk priorities are 0.077 for decision uncertainty, 0.231 for panic and 0.692 for fatal injury for physiological impact.

Table 5 . The $3 \times 3$ matrix for priorities of physiological impact.

\begin{tabular}{|l|c|c|c|c|}
\hline & Panic & $\begin{array}{c}\text { Nonfatal } \\
\text { Injury }\end{array}$ & Fatal Injury & Priorities \\
\hline Panic & 1 & $1 / 3$ & $1 / 9$ & 0.077 \\
\hline Nonfatal Injury & 3 & 1 & $1 / 3$ & 0.231 \\
\hline Fatal Injury & 9 & 3 & 1 & 0.692 \\
\hline
\end{tabular}

The priority vectors are combined into a single (or global) priority vector for evaluating the risks associated with the use of lifts in fire emergencies (see Table 6).

Table 6. Risk global priorities

\begin{tabular}{|l|c|c|c|}
\hline & \multicolumn{3}{c|}{ Global Priorities } \\
\hline \multicolumn{1}{|c|}{ Risk Category } & Evaluation & Result & Applied to Parameters \\
\hline Decision Uncertainty & $0.066 \times 0.11+0 \times 0.89$ & 0.0074 & $p_{1,} p_{2}$ and $p_{3}$ \\
\hline Panic & $0.319 \times 0.11+0.077 \times 0.89$ & 0.1036 & $p_{4}$ and $p_{5}$ \\
\hline Nonfatal Injury & $0.615 \times 0.11+0.231 \times 0.89$ & 0.2732 & $p_{6}$ and $p_{7}$ \\
\hline Fatal Injury & $0 \times 0.11+0.692 \times 0.89$ & 0.6158 & $p_{6}$ and $p_{7}$ \\
\hline Total & & 1.0 & \\
\hline
\end{tabular}




\section{Parametric Value of Decision Uncertainty}

Decision uncertainty represents a low level anxiety of evacuees. The parametric value of decision uncertainty is related to lift transportation time, lift waiting time and the proportion of the population that rely on lift for evacuation. The values of these parameters were determined from available literature data and the result of non-deterministic evacuation modeling.

General statistics of evacuation by lifts is not available in the literature. The data by Sekizawa et al. [24] was therefore used in the current study. In a particular post incident survey in Japan, Sekizawa et al. reported that $47 \%$ residents used lifts and $42 \%$ residents used stairs and $7 \%$ residents used both to evacuate an apartment during a fire emergency. A small $4 \%$ were shown as others. Splitting this proportion and the proportion that used both lift and stair, an estimate of $52.5 \%$ was given to the proportion of lift use and the rest to stair use. Considering the average number of evacuees for lift evacuation, the required timings and number of evacuees in queue are determined from ARENA simulation software [25]. A stochastic evacuation model was developed for a 38 storey apartment building within the context of occupant load (32 persons on each floor level) and building space, where the evacuation time would tend to be constrained by human factors (social, physiological and psychological characteristics) and limited by flow rate capacities of evacuation routes. Recent census result in Australia indicates that the percentage of aged and disabled was $16 \%$ [8]. The lift evacuation time period $\left(t_{L W}+t_{L T}\right)$, the number of evacuees in queue and the percentage of aged and disabled persons are given as:

- Average total of $t_{L W}$ and $t_{L T}\left(p_{1}\right)$

- Average number of evacuees in queue $\left(p_{2}\right)$

- Percentage of aged and disabled persons $\left(p_{3}\right)$

$$
\begin{aligned}
& =449 \text { seconds } \\
& =3.51 \text { persons } / \text { floor } \\
& =16 \% \text { population }
\end{aligned}
$$

\section{Parametric Value of Panic}

Panic may be regarded as a higher level anxiety of evacuees in comparison to decision uncertainty. It may be attributed to concerns for non-availability of lifts and fire escape routes. A survey was conducted in high-rise apartments with the objectives of determining comforts of high-rise living in Hong Kong [26]. In response to a question relating to the disadvantages of high-rise living, 36\% population reported fire escape, $20 \%$ reported lift breakdown, $2 \%$ reported strong wind, $2 \%$ reported heat and $4 \%$ reported lack of play areas. The $20 \%$ population was concerned with the non-availability of lifts in the apartment building. The $36 \%$ population was concerned with the fire escape. The concern of fire escape occurs due to the presence of visual threat in the evacuation route (which is ultimately time to exceed the tenable limit for visual smoke). Again, these particular results were used in lieu of general statistics due to the lack of the latter. The evacuees' concern of non-availability of lift and fire escape is given in the form of population as:

- Evacuees' concern for non-availability of lifts $\left(p_{4}\right) \quad=20 \%$

- Evacuees' concern for fire escape $\left(p_{5}\right) \quad=36 \%$

\section{Parametric Value of Injuries}

The causes of fatal injuries in residential fires are interpolated as the fatal injuries caused by hazardous exposure in evacuation routes. Miller [9] showed that $28.5 \%$ of evacuees were found dead while attempting to evacuate the buildings, but did not give the locations of victims. The findings of residential fire injuries are assumed for evacuation routes in apartment buildings, although there may be fewer victims of burns/ incinerations and more victims of toxic gases in evacuation routes. The following data are given [9]:

- Causes of injuries due to smoke asphyxiant toxic gases, fire and temperature/ incineration $\left(p_{6}\right)=$ 174 cases

- Causes of injuries that precipitate deaths from pre-existing health conditions $\left(p_{7}\right)=11$ cases

The safety index [27] is used for determining the fatal injury caused due to smoke asphyxiant toxic gases and temperature (the probability of time period for occupants' evacuation is less than the probability of time to exceed the tenability limits). 


\section{Parametric Global Weights}

Table 7 gives the global weights of parameters. The parametric global weights were obtained from the individual values of the parameters (for example $p_{1}$, 449 seconds is $58.84 \%$ of 763 seconds - the lift waiting and transportation time for the entire population, similarly for $p_{2}, 3.51$ persons is $10.96 \%$ of 32 persons - the floor population). However, the weights for parameters $p_{1}$ to $p_{7}$ did not share the same basis as the values are based on evacuation periods, percentage of evacuees, evacuees' response and number of fatal injury obtained under different conditions. Under such conditions, multi-criteria decision approach is the most appropriate method to determine the group weights and global weights.

Table 7. Parametric values and weights relating to building evacuation

\begin{tabular}{|c|c|c|c|c|c|c|}
\hline $\begin{array}{c}\text { Risk } \\
\text { Category }\end{array}$ & $\begin{array}{c}\text { Parameter } \\
\text { Index } \\
i\end{array}$ & $\begin{array}{l}\text { Individual } \\
\text { Value }\end{array}$ & $\begin{array}{c}\text { Individual } \\
\text { Percent } \\
(\%)\end{array}$ & $\begin{array}{c}\text { Group } \\
\text { Percent } \\
\text { (\%) }\end{array}$ & $\begin{array}{l}\text { Group } \\
\text { Weight }\end{array}$ & $\begin{array}{c}\text { Global } \\
\text { Weight } \\
\left(w_{i}\right)\end{array}$ \\
\hline \multirow{3}{*}{$\begin{array}{l}\text { Decision } \\
\text { uncertainty }\end{array}$} & 1 & $449 \mathrm{~s}$ & 58.84 & 68.58 & 0.6858 & 0.0051 \\
\hline & 2 & $3.51 \mathrm{~s}$ & 10.96 & 12.77 & 0.1277 & 0.0009 \\
\hline & 3 & $16 \%$ & 16 & 18.65 & 0.1865 & 0.0014 \\
\hline \multirow[t]{2}{*}{ Panic } & 4 & $20 \%$ & 20 & 35.7 & 0.3570 & 0.0370 \\
\hline & 5 & $36 \%$ & 36 & 64.3 & 0.6430 & 0.0666 \\
\hline \multirow[t]{2}{*}{ Injuries } & 6 & 174 cases & 94.05 & 94.05 & 0.9405 & 0.8361 \\
\hline & 7 & 11 cases & 5.95 & 5.95 & 0.0595 & 0.0529 \\
\hline \multicolumn{6}{|l|}{ Total } & 1.0000 \\
\hline
\end{tabular}

\section{Value Functions}

The purpose of introducing value functions is to normalize dimensional risk parameters with given lower and upper bounds into non-dimensional parameters with 0 to 1 or 0 to $100 \%$ scale. The values of the value functions are obtained from various modelling and analysis for all the concept designs and evacuation strategies. The parameters are multi-dimensional and require deriving a value function.

The value function for $p_{1}$ is determined with the help of ARENA stochastic models. The parameter $p_{1}$ varied from 338 seconds $\left(t_{S T}\right)$ to 763 seconds $\left(t_{L W}+t_{L T}\right)$. The longest time is given a value function of 100 and minimum time is given a value function of 0 . In mathematical notation, it can be written as:

- $\quad v_{1}(763)=100$

- $v_{1}(338)=0$

Any value of $p_{1}$ between $338 \mathrm{~s}$ and $763 \mathrm{~s}$ was then translated to a value between 0 and 100 . However, the translation was not linear. It is rather a bisection curve, which divides the parametric value equally (see Fig. 2). Two intermediate values of the value function were determined according to the variable that determined the parameter $p_{1}$. This variable was a fraction of the population that uses lifts to evacuate the building. The lift evacuation time for $50 \%$ population was determined via modeling to be about 450 seconds. Therefore, $v_{1}(450)=50$. Similarly, it was determined that $v_{1}(619)=75$. The value function as defined above is skewed upward as shown in Fig. 2 and is more sensitive to initial increase of evacuation time from the lower bound value of $338 \mathrm{~s}$ than to large evacuation times near the upper bound.

The value functions are derived proportionately from the extreme values for remaining parameters. The Fire Dynamics Simulator (FDS) model [28] was used to determine the available safe evacuation time (ASET). The results are compared with the required safe evacuation time (RSET) for determining the impact on building occupants. The reliability of lift operational mechanism is evaluated from standard risk assessment techniques such as fault tree and event tree analyses [29]. The results demonstrated that the lifts protected with lobby are significantly more reliable in comparison to the lifts without lobby. Protected lift lobbies provided adequate safety against the temperature rise in lift machine room (LMR). The probability 
of electric power failure due to fire in a residential unit was small. The results from building evacuation models, fire hazard computational model and probabilistic risk analysis are used for remaining parameters.

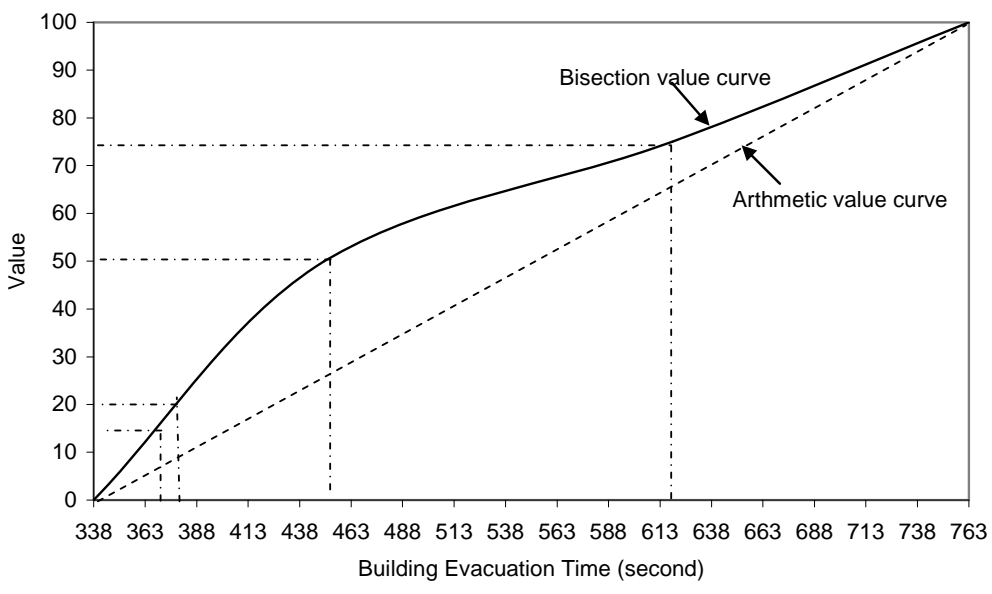

Fig. 2. Value functions for building evacuation times

\section{Analysis of Results}

\section{Values for Risk Assessment}

The value functions are multiplied by the weights and all the weighted grades for $p_{1}$ to $p_{7}$ are added according to Eq. 1 to give a final grade of risk. Table 8 indicates the overall value of risk obtained for the five concept design options.

Table 8. Risk values for various concept design options

\begin{tabular}{|c|c|c|c|c|c|c|}
\hline Parameter & Global Weight $\left(\boldsymbol{w}_{\boldsymbol{i}}\right)$ & $\mathbf{A}$ & $\mathbf{B}$ & $\mathbf{C}$ & $\mathbf{D}$ & $\mathbf{E}$ \\
\hline$p_{1}$ & 0.0051 & 0.507 & 0.507 & 0.507 & 0.101 & 0.076 \\
\hline$p_{2}$ & 0.0009 & 0.094 & 0.094 & 0.094 & 0.001 & 0.014 \\
\hline$p_{3}$ & 0.0014 & 0.046 & 0.046 & 0.046 & 0.138 & 0.015 \\
\hline$p_{4}$ & 0.0370 & 3.699 & 0.037 & 0.037 & 0.000 & 0.037 \\
\hline$p_{5}$ & 0.0666 & 6.661 & 5.995 & 0.000 & 5.462 & 8.327 \\
\hline$p_{6}$ & 0.8361 & 83.610 & 57.499 & 28.093 & 55.183 & 49.33 \\
\hline$p_{7}$ & 0.0529 & 5.290 & 3.491 & 0.000 & 1.746 & 1.746 \\
\hline Total Risk & 1 & 99.908 & 67.670 & 28.778 & 62.631 & 59.545 \\
\hline
\end{tabular}

\section{Sensitivity Study}

To determine the robustness of results, a sensitivity analysis is conducted against the weightings used in the risk analysis for panic $\left(w_{4}\right.$ and $\left.w_{5}\right)$. If panic is given zero weighting, two parameters $\left(p_{4}\right.$ and $\left.p_{5}\right)$ would have zero weighting. On the other hand if they are given $100 \%$ weighting, the remaining five parameters $\left(p_{1}, p_{2}\right.$, $p_{3}, p_{6}$, and $p_{7}$ ) would have zero weighting. Fig. 3 shows how the total risk values for the different design options vary with changes in the weighting placed on panic. The use of protected lift system to evacuate $25 \%$ of the population and the remaining population by stairs (Option E) would have total risk values of 51.18 and 8.36 when the value of weight given for panic was varied from 0 to $100 \%$. Similarly, the concept design Option B would have risk values of 61.64 and 6.03 and the concept design Option D would have risk values of 57.17 and 5.46 at the two extremes. Comparing these risk values, it can be seen that the safe design option $\mathrm{E}$ has changed to option $\mathrm{D}$ at 62 (equivalent risk) for the case of the highest weight given to panic $(100 \%)$. The safe design option $\mathrm{E}$ is sensitive to the slight variation in the proportion of building population. The most safe evacuation concept design option (Option $\mathrm{C}$ ) is not affected by the change. The risk value for unprotected lift lobby (Option A) remains relatively higher than those for stairs (Option D) despite the change of weight values for panic. 


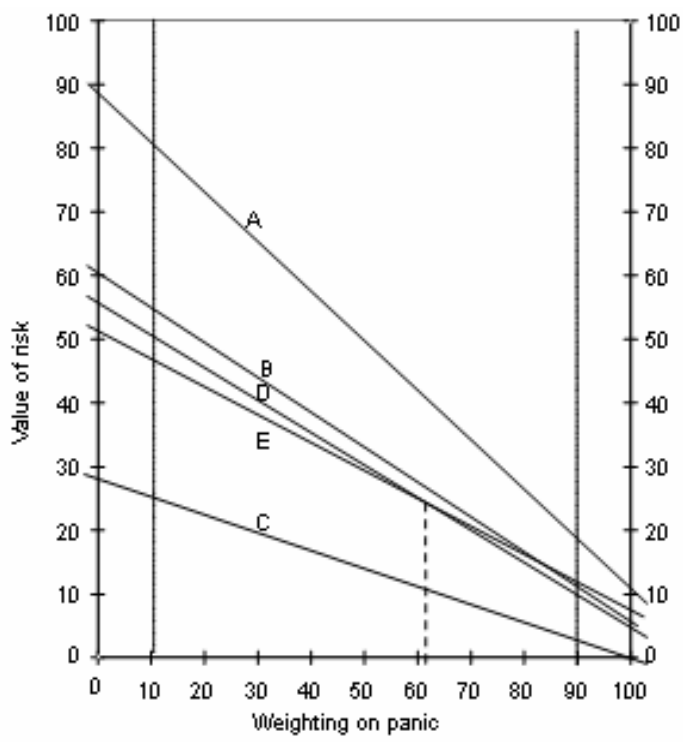

Fig. 3. Sensitivity analysis for different weights placed on panic.

\section{Analysis of Results}

The overall risk values calculated for the five design options are shown in Fig. 4. If the stair alone evacuation (Option D) is considered as an acceptable evacuation design, then the lift with simply protected lobby for one-fourth of the building population (Option E) and double protected lift lobby (Option C) provide acceptable alternatives since the latter two have lower associated risk than the former. Lifts with unprotected lobby (Option A) has the highest risk, followed by lifts with simply protected lobby for entire population evacuation (Option B). The results also show that the risks are considerably reduced by providing protected lift lobby. A combination of lifts and stairs provide a lower level of risks in comparison to stair alone evacuation (Option D) or lift alone evacuation with the same lobby protection (Option B).

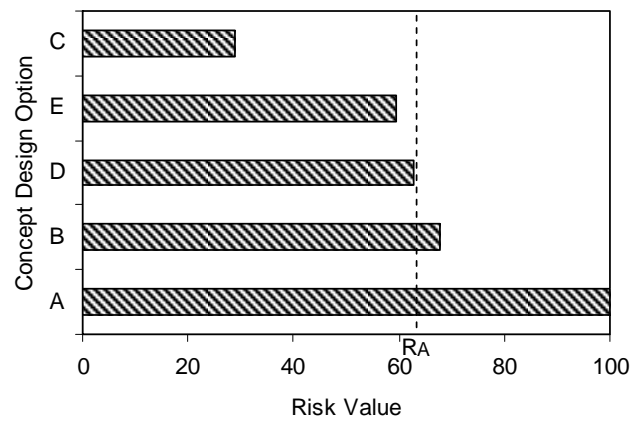

Fig. 4. Risk values of various concept design options.

\section{CONCLUSIONS}

A risk assessment was conducted using MODA method for the use of lift in emergency evacuation. Multiple risk parameters in relation to human behavioural response, fire hazard exposure and reliability of lift operational mechanism were included in the assessment. The method was applied to a particular high 
rise apartment building and a number of design options were compared. The results of the assessment are summarized as follows:

- Lifts with unprotected lobby contribute to the maximum for risks.

- Lift with protected lobby does not provide adequate safety in comparison to stair for the entire building population. Overall risks of lifts with protected lobby were slightly higher than the risks of stair system.

- A combined system of lifts with protected lobby for one-fourth of population and stair for threefourth of population can provide adequate safety in comparison to individual system alone (lifts or stairs).

- Lifts with double protected lobby provides a better performance.

The MODA method provides a versatile means for risk assessments. It is based on a comparative study of multiple options and incorporates multiple risk attributes into the evaluation. In its application to fire risk assessment, the method is linked to other means of evaluations such as the ASET/RSET analysis, stochastic modeling and safety index analysis. The MODA method involves the ranking of level of importance for multiple risk attributes. This ranking is still by and large empirical and, to a degree, subjective. Further research is required to establish a statistical database which can be used to justify the ranking. Input from multiple stakeholders in the fire engineering brief process, as recommended by the International Fire Engineering Guidelines, can also be adopted as a way to minimise subjectivity in the ranking.

The current study did not include the cost-effectiveness analysis in the risk assessment, although in theory such an inclusion is achievable.

\section{REFERENCES}

[1] Klote, J.H., (1982), "Elevators as a Means of Fire Escape", American Society of Heating Refrigerating and Air Conditioning Engineers Transactions, NBSIR 82-2507; p. 1-40.

[2] Pauls, J.L., Gatfield, A. J. and Juillet, E., (1991), "Elevator Use and for Egress: The Human Factors Problems and Prospects", ASME Symposium on Fire and Elevators, Baltimore, MD, Feb 19-20, ASME, New York, NY, p. 63-75.

[3] Bukowski, R.W., Burgess, S.R., Reneke, P.A., Editors (2003), "Collected Publications Related to the Use of Elevators during Fires", NIST Special Publication 983, Building and Fire Research Laboratory, NIST, USA.

[4] Kuligowski, E., (2003), "Elevators for Occupant Evacuation and Fire Department Access", Proceedings of the CIB-CTBUH International Conference on Tall Building, Malaysia.

[5] Kuligowski, E., and Bukowski, R.W., (2004), "Design of Occupants Egress Systems for Tall Buildings", National Institute of Standards and Technology, CIB, USA, p. 1-10.

[6] So, A., and Yu, J. (2003), "Lift Logic", Fire Prevention - Fire Engineers Journal, August Issue, Gloucestershire, UK, p. 26-28.

[7] Ebihara, M., Sekizawa, A., Nakahama, S., Notake, H., Ikehata, Y. (2004), “Analysis on Efficiency of Evacuation Using Elevators in a High-Rise Building", Human Behavior in Fire: Public Fire Safety - Professionals in Partnership. International Symposium, 3rd. Proceedings. September 1-3, 2004, Belfast, N. Ireland, Interscience Communications Ltd., London, England, 377-397 p.

[8] ABS (2004), "Housing and Lifestyle: High Rise Living", Australian Bureau of Statistics, Report No. 4102.0 .

[9] Miller, I., (2005), "Human Behaviour Contributing to Unintentional Residential Fire Deaths 1997 -2003”, New Zealand Fire Service Commission Research Report Number 47.

[10] Koshak, J. (2003), "Elevator Evacuation in Emergency Situations”, ASME, p. 1-6.

[11] Allen, T., (2004), "Early Evacuation Elevator Operation", Use of Elevators in Fires and Other Emergencies Workshop Proceedings, Building Performance Research Institute, March 2-4, Atlanta, GA, 1-8 pp. 
[12] Klote, J.H. (2003), "Analysis of the Life Safety Consequences of Smoke Migration through Elevator Shafts", American Society of Mechanical Engineers, ASME, p. 1-20.

[13] Aloi, S. and Rogers, J. (2002), "Reach of the Sky", Fire Prevention \& Fire Engineers Journal, Volume 62, No. 219, FPA, London, UK.

[14] Bukowski, R. W., (2005), "Protected Elevators For Egress And Access During Fires In Tall Buildings", Workshop on Building Occupant Movement During Fire Emergencies, Proceedings, June 10-11, 2004, Gaithersburg, MD, Peacock, R. D., Kuligowski, E. D., Editors, 14-21 p.

[15] Nakahama, S., Ebihara, M., Sekizawa, A., Ikehata, Y., Notake, H., (2005), "Examination of Feasibility of Elevator Evacuation Based on Risk Assessment", Fire Safety Science, Eighth $\left(8^{\text {th }}\right)$ International Symposium, International Association for Fire Safety Science (IAFSS), September 18-23, Beijing, China, IAFSS, Boston, MA, Gottuk, D. T., Lattimer, B. Y., Editors, 611-622 p, doi:10.3801/IAFSS.FSS.8-611

[16] ABCB, (2005), International Fire Engineering Guidelines, Australian building code Board, Canberra, Australia.

[17] Clemen, R.T., (1996), "Making Hard Decisions: An Introduction to Decision Analysis", $2^{\text {nd }}$ Edition, Belmond, California - Duxbury Press.

[18] Balson, W. E., J. L. Welsh, D. S. Wilson, (1992), "Using Decision Analysis and Risk Analysis to Manage Utility Environmental Risk", Interfaces 22(6), p. 126-139.

[19] French, S., (1996), "Multi-Attribute Decision Support in the Event of a Nuclear Accident", Journal of Multi-Criteria Decision Analysis 5, p. 39-57, doi:10.1002/(SICI)1099-1360(199603)5:1<39::AID-MCDA109>3.3.CO;2-H

[20] Dyer, J., Edmunds, T., Butler, J., Jia, (1998), “A Multi-Attribute Utility Analysis of Alternatives for the Disposition of Surplus Weapons-Grade Plutonium”, Operations Research 46 p. 749-762.

[21] Lee, W. B., Lau, H., Liu, Z, and Tam, S., (2001), “A Fuzzy Analytical Hierarchy Process Approach in Modular Product Design", Expert System, 18 (1), p. 32-42, doi:10.1111/1468-0394.00153

[22] Edwards, W., (1977), "Social Utilities", Decision and Risk Analysis Powerful New Tools for Management, The Engineering Economist - Summer Symposium Series VI, ASEE.

[23] Saaty, T.L. (1980), "The Analytic Hierarchy Process", McGraw-Hill, New York.

[24] Sekizawa, A., Nakahama, S., Notake, H., Ebihara, M., and Ikehata Y., (1996), "Study on Feasibility of Evacuation using Elevators in a High-rise Building", University of Tokyo, Taisei Corporation and Shimizu Corporation.

[25] Rockwell, (2000), “ARENA 5.0 Version”, Rockwell Software Inc., USA.

[26] Mori Building Co. Ltd and University of Hong Kong, (2002), “A Survey on Residents' Responses to High-Rise Living in Hong Kong", Mori Building.

[27] Cornell, C.A. (1969), “A Probability-Based Structural Code”, ACI Journal, Volume 66(12), p. 974-985.

[28] McGrattan, K.B., Forney, G.P., Floyd, J.E., Hostikka, S. and Prasad, K., (2004), "Fire Dynamics Simulator - Version 4.07”, Fire Research Division, NIST, USA.

[29] Sharma, T.S., He, Y. and Mahendran, M., (2007), "Reliability of Lift Operational Mechanism during Fire Emergencies", Proceedings of International Symposium on Elevator Evacuation during High Rise Fire, Shanghai, China. 